B. PŁONKA*,\#, M. RAJDA*, Z. ZAMKOTOWICZ*, J. ŻELECHOWSKI*, K. REMSAK*, P. KORCZAK*, W. SZYMAŃSKI*, L. SNIEŻEK**

\title{
STUDIES OF THE AA2519 ALLOY HOT ROLLING PROCESS AND CLADDING WITH EN AW-1050A ALLOY
}

The objective of the study was to determine the feasibility of plastic forming by hot rolling of the AA2519 aluminium alloy sheets and cladding these sheets with a layer of the EN AW-1050A alloy. Numerous hot-rolling tests were carried out on the slab ingots to define the parameters of the AA2519 alloy rolling process. It has been established that rolling of the AA2519 alloy should be carried out in the temperature range of $400-440^{\circ} \mathrm{C}$. Depending on the required final thickness of the sheet metal, appropriate thickness of the EN AW-1050A alloy sheet, used as a cladding layer, was selected. As a next step, structure and mechanical properties of the resulting AA2519 alloy sheets clad with EN AW-1050A alloy was examined. The thickness of the coating layer was established at $0,3 \div 0,5 \mathrm{~mm}$. Studies covered alloy grain size and the core alloy-cladding material bond strength.

Keywords: Al alloys, rolling, cladding, mechanical properties, structure.

\section{Introduction}

The use of wrought aluminium alloys mainly depends on their mechanical properties, structure, corrosion resistance, etc. In some applications of these alloys, appropriate plastic properties are desired or even required, including the elongation, reduction of area, and adequate interval between yield strength and tensile strength. A good example are all the elements whose main task is to absorb energy, e.g. the elements used in controlled crumple zones, bumpers for vehicles, or multi-layer passive ballistic shields. In the group of aluminium alloys that can meet the imposed requirements there are alloys from the $\mathrm{AlCuMgMn}$ system, characterized by high strength combined with adequate ductility. An example of the alloy with these properties is AA2519 [1]. Modern materials science develops increasingly sophisticated materials, produced in solid form or as layered products. Aluminium alloys bonded, preferably by diffusion, with other materials providing higher strength and stiffness, such as e.g. titanium metal, are a good example of recent advances in this field. One of the technologies of joining metals together is by explosive bonding $[2,3]$. This technology provides diffusion bonds characterized by very high strength parameters. To bond aluminium alloy with other metals in this process, inserts made of pure aluminium are to be used or alloys must be properly prepared, i.e. have an intermediate cladding layer [4]. The deposition of an intermediate cladding layer can be accomplished, for example, in the technological process of plastic working such as rolling. [5] Clad strips have been manufactured for years from different metals and alloys to enhance the aesthetics and corrosion resistance of rolled products. In Polish aluminium industry, the production of clad aluminium strips started in the early years of the twenty-first century in response to the needs of the automotive industry. As a result of numerous technological experiments, the domestic aluminium industry has over the years optimized the chemical composition of both the core and the cladding layer. Progressively smaller and smaller thicknesses of the clad strips were introduced into production. The strips made in Poland from the EN AW3003 alloy clad with the EN AW-4045 alloy (5\%, 7.5\%, 10\% of the base strip thickness) are offered in the thickness range from $0.050 \div 3.0 \mathrm{~mm}$, in a width of $12 \div 1500 \mathrm{~mm}$, and in the $\mathrm{O}, \mathrm{H} 14$ / H24 or H16 / H26 condition [6]. The production of clad bimetallic strips requires preparation of feedstock in the form of bimetallic blocks. Details are industrial secret. Clad strips are rolled in a conventional process undergoing the required strain hardening, followed by interoperational annealing removing the effects of deformation and enabling further rolling.

Following the guidelines set out previously, the main problem which this study should solve is the development of an optimal technology for the manufacture of sheets from AA2519 alloy without and with the cladding layer made of pure aluminium, designed for further explosive bonding with titanium alloy sheets. In particular, in this work, it has been scheduled to determine the parameters of the plastic working process to obtain hot rolled clad sheets, and specifically to determine the parameters of the sheet surface preparation for cladding, the rolling reduction, the temperature of the rolling process, and thickness of the cladding layer. The plan of research anticipated the manufacture of AA2519 alloy by melting, casting of slab ingots, and rolling them to a thickness of $3 \div 10 \mathrm{~mm}$.

INSTITUTE OF NON-FERROUS METALS, LIGHT METALS DIVISION, 19 PILSUDSKIEGO STR., 32-050 SKAWINA, POLAND 


\section{Research methodology}

The AA2519 alloy proposed for studies is included in the family of $2 \mathrm{XXX}$ series aluminium alloys designed for plastic working. Some alloys in this group achieve after heat treatment the highest mechanical properties among all the aluminium alloys [7]. They successfully combine the high strength with a relatively high ductility - crucial for the later explosive bonding. These alloys are used for different types of structures, also heavily loaded. The key issue in the present study was to obtain in the tested AA2519 alloy an ultrafine structure with a significant effect on the mechanical properties in accordance with the HallPetch formula. According to the authors' experience, the addition of $\mathrm{Zr}$ in amounts of $\sim 0.2-0.3 \%$ makes this alloy resistant to recrystallization, which is essential for the stability of mechanical properties at elevated temperatures due to a homogeneous dispersion of the $\mathrm{Al}_{3} \mathrm{Zr}$ phases $[8,9]$. Therefore, choosing proper parameters of the casting process and homogenizing annealing is so important, since on these parameters depends the refinement of the added zirconium, which will appear in the solution in the form of nanometric precipitates (about 20-40nm), acting as inhibitors of the recrystallization process. In this way, the AA2519 alloy products acquire an ultrafine structure, which in turn gives the material characterized by high ductility and strength [10]. The feedstock for further studies was prepared on a testing stand for semi-continuous vertical casting of slab ingots for rolling. Rolling tests were conducted on the examined materials in the "Łabędy" Nonferrous Metals Rolling Mill. The next step was test cladding of the AA2519 alloy with EN AW-1050 alloy during the hot rolling process. Bonding of aluminium alloy by hot plastic working is expected to reduce the number of single layers required for further explosive bonding and can improve the quality of bonds obtained in the Al-Ti layered material. The resulting materials were subjected to structure analysis to check if the quality parameters set out for the sheet metal without and with aluminium cladding were achieved.

\section{Test results}

\subsection{Casting of AA2519 alloy slab ingots for rolling trials}

Slab ingots were cast on a device for semi-continuous casting operating in IMN-OML Skawina, using flat moulds measuring $300 \times 125 \mathrm{~mm}$ (Fig.1). To avoid the risk of crack formation, the ingots were homogenized immediately after casting. The chemical compositions of the tested materials are given in Table 1. From ingots, blocks $340 \mathrm{~mm}$ long were cut out, and after peeling they were used as a feedstock for the rolling process (Fig. 2).

In the first series of casting the slab ingots from the AA2519 alloy, the metal was fed to the mould by one double float. The result was excessive metal cooling on the short sides of mould and differences in the solidification conditions. The consequence was strong heterogeneity of structure, and ingots with poor surface quality and cracks formed in them. Figure 3 shows microstructure in various places of the ingot starting from the surface (left) and moving towards the centre.

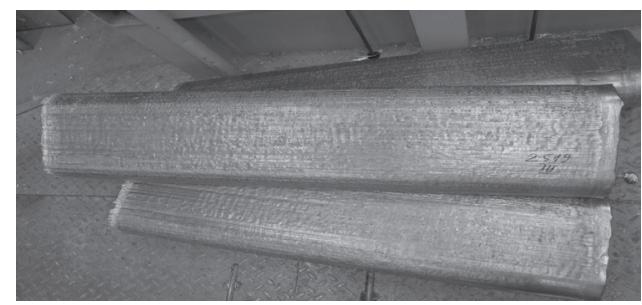

Fig. 1. Photograph of AA2519 alloy ingots

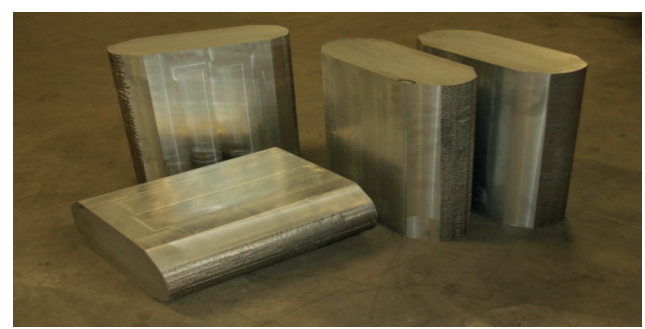

Fig. 2. Blocks prepared for the rolling process

TABLE 1

The chemical composition of AA2519 alloy

\begin{tabular}{|c|c|c|c|c|c|c|c|c|c|}
\hline \multirow{2}{*}{ Alloy } & \multicolumn{9}{|c|}{ Contents [\%] } \\
\hline & $\mathbf{F e}$ & Si & $\mathbf{C u}$ & $\mathbf{T i}$ & Mn & Mg & $\mathbf{V}$ & $\mathbf{Z r}$ & B \\
\hline Standard - until & 0,30 & 0,25 & 6,40 & 0,10 & 0,25 & 0,40 & 0,15 & 0,25 & \\
\hline from & & & 5,80 & 0,02 & 0,10 & 0,20 & 0,05 & 0,15 & \\
\hline AA2519 & 0,13 & 0,12 & 6,29 & 0,10 & 0,16 & 0,38 & 0,10 & 0,18 & 0,005 \\
\hline
\end{tabular}

a)

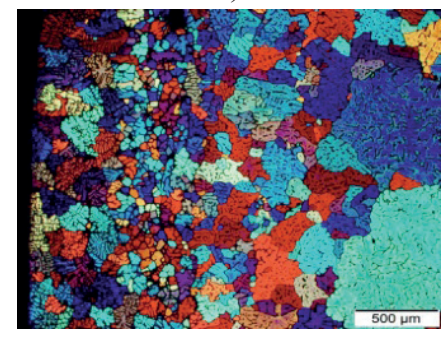

b)

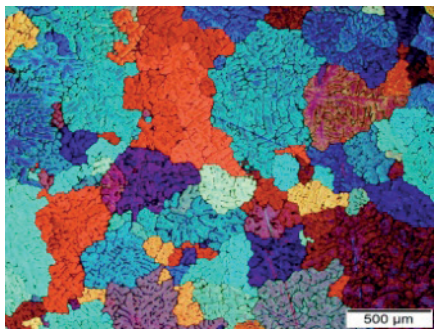

c)

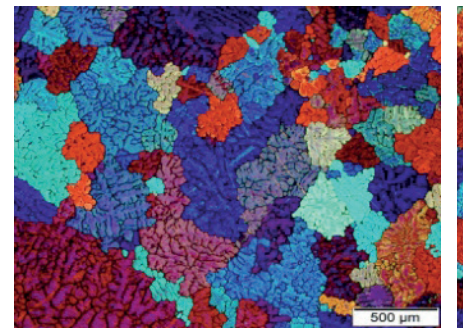

d)

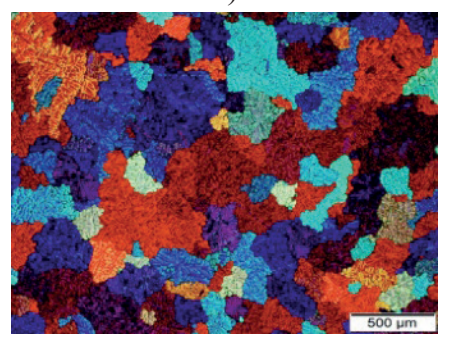

Fig. 3. Examples of microstructure (grain size) obtained in selected areas of the ingot moving from the surface A towards the centre D (mag. 50x) 
In samples taken from the boundary zone of the ingot (from area 1, 4 and 5-Fig. 4A), the grain size was measured along the line running from the edge of the ingot towards the centre. The results are compared in Figure 4.

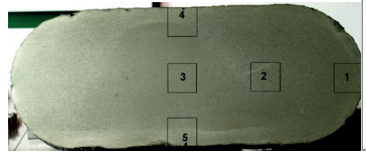

b)

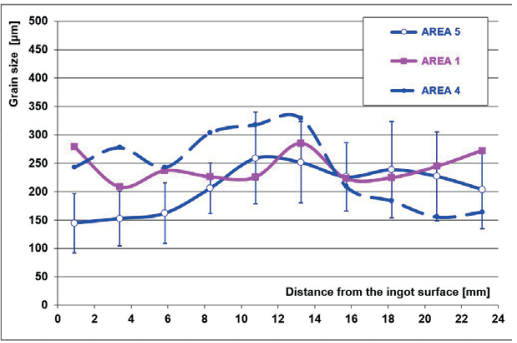

Fig. 4. Areas of taking a sample (A) and the distribution of grain size values measured along the line running from the edge of the ingot towards the centre (B)

To reduce the heterogeneity of the ingot structure, the metal feeding system was changed, introducing a new divider allowing the metal to be brought symmetrically to the two distant places by two floats. The effect of the introduced changes was verified during subsequent trials, casting ingots from the AA2519 alloy. The microstructure of the AA2519 alloy ingots after changes in the pouring system was much more homogeneous with very fine grains and the subsurface zone of up to $6 \mathrm{~mm}$ clearly visible. Examples of microstructures are shown in Figure 5.

Aluminium alloys from the $2 \mathrm{xxx}$ series are characterized by a very wide range of solidification temperatures, which is the source of numerous troubles during casting. In addition to the formation of heavy subsurface segregations of components and "bleeding" of eutectic, both of which have a significant impact on the ingot surface quality, there is also the phenomenon of hot cracking. The introduction of a new divider significantly improved the surface quality of slab ingots and reduced the grain size variations.

\subsection{Rolling of AA2519 alloy sheets}

Test rolling of ingots was carried out on a duo rolling mill in the "Labędy" Nonferrous Metals Rolling Mill. Ingots were peeled prior to rolling removing the surface skin containing oxides. Then they were heated in resistance furnace to temperatures in the range of $400-440^{\circ} \mathrm{C}$. Selected parameters of the rolling process are shown in Table 2.

Ingots were preheated only once, and from this temperature they were rolled to final size. Rolls were cooled, and therefore ingots designed for the sheets of smaller thickness and obviously needing more passes were preheated to higher temperature. Figure 6 shows the ingot preheated before the first pass through a rolling mill. Ingots after peeling had the size of $300 \times 120 \mathrm{~mm}$ and $340 \mathrm{~mm}$ length. The first $5 \div 6$ passes of rolling were made in the transverse direction to expand the ingot to a width of about $600 \mathrm{~mm}$ (Fig. 7). Figure 8 shows the whole strip at the end of the rolling process, while Figure 9 shows photographs of the finished sheets of 500x1000mm size and thicknesses of $3 \mathrm{~mm}, 5 \mathrm{~mm}$ and $10 \mathrm{~mm}$. a)

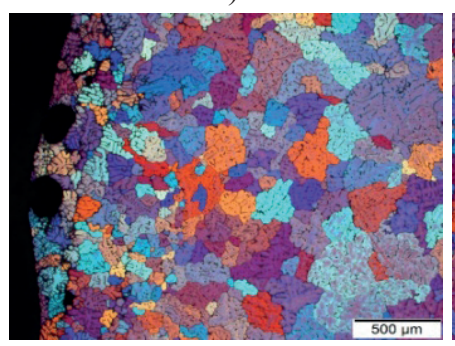

$279 \mu \mathrm{m}$ b)

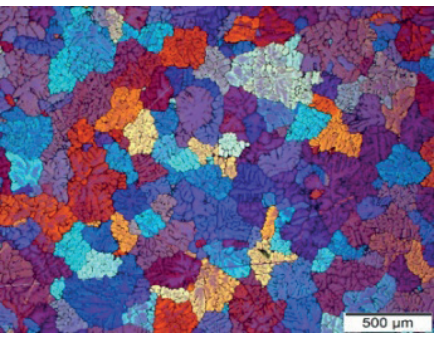

Average grain size c)

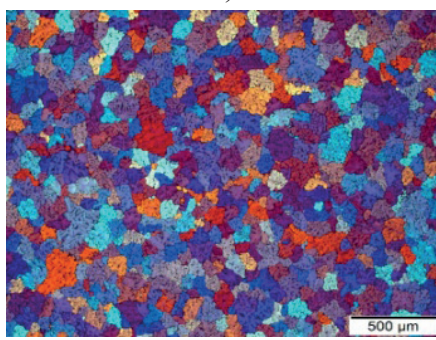

$162 \mu \mathrm{m}$ d)

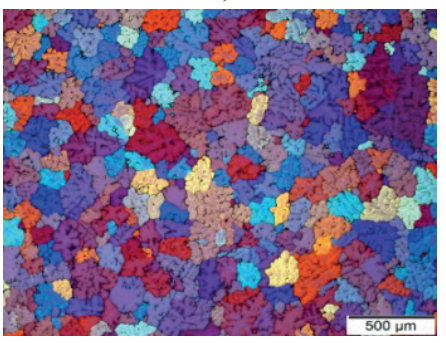

$212 \mu \mathrm{m}$

Fig. 5. Examples of microstructures and grain size in selected areas of the ingot (after changes in the pouring system) moving in the direction from the surface A towards the centre D

TABLE 2

Selected parameters of the AA2519 alloy sheet rolling process

\begin{tabular}{|c|c|c|c|c|}
\hline \hline \multirow{2}{*}{$\begin{array}{c}\text { Billet temperaturę before } \\
\text { rolling [oC] }\end{array}$} & \multirow{2}{*}{$\begin{array}{c}\text { Billet temperaturę after } \\
\text { rolling [oC] }\end{array}$} & \multicolumn{2}{|c|}{ Sheet dimension after rolling } & \multirow{2}{*}{ Hot deformation [\%] } \\
\cline { 2 - 4 } & 320 & Thickness [mm] & Lenght [mm] & \\
\hline 400 & 305 & 10 & 1600 & 92 \\
\hline 420 & 300 & 3 & 3200 & 96 \\
\hline 440 & 3000 & 97,5 \\
\hline
\end{tabular}




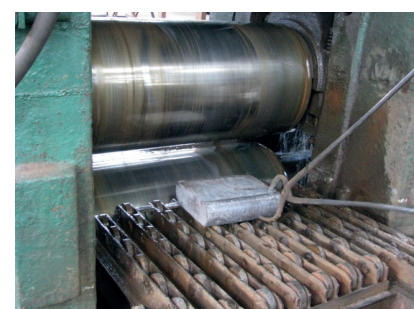

Fig. 6. The first pass of AA2519 alloy ingot through a rolling mill

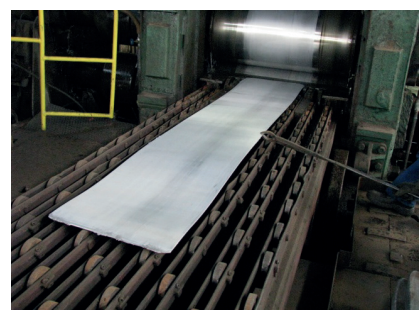

Fig. 8. The AA2519 alloy strip after rolling

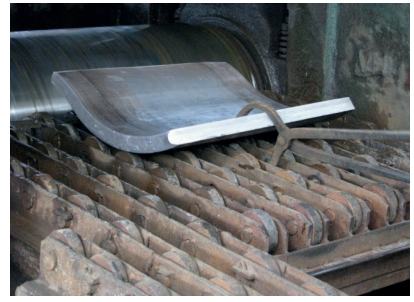

Fig. 7. Ingot widened after the cross-rolling

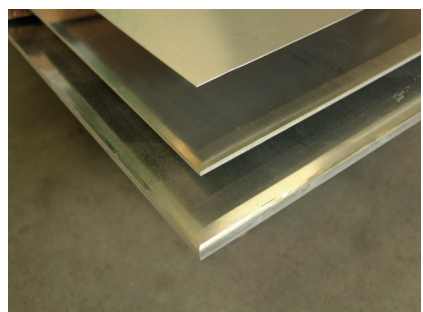

Fig. 9. Finished AA2519 alloy sheets with thicknesses of $3 \mathrm{~mm}$, $5 \mathrm{~mm}$ and $10 \mathrm{~mm}$
From the finished sheets, metal samples were cut out along and across the rolling direction to better reveal the size of grains in the microstructure for each sheet thickness. Photographs of microstructures obtained in the rolled sheets are shown in Figures 10 to 12.
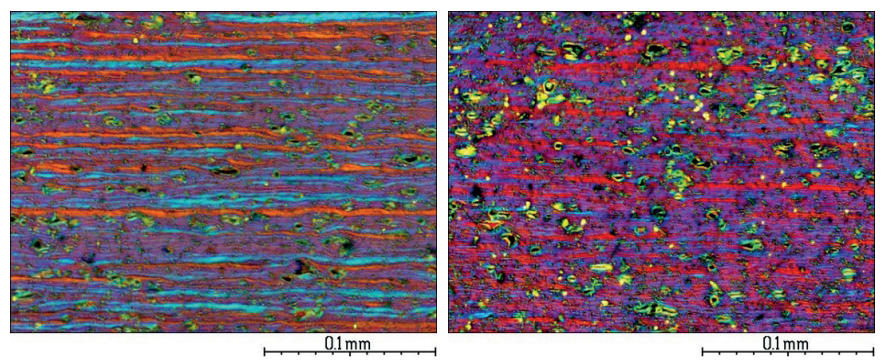

Fig. 10. Photographs of microstructure obtained in the $3 \mathrm{~mm}$ thick AA2519 alloy sheet - section longitudinal (A) and transverse (B) to the sheet rolling direction
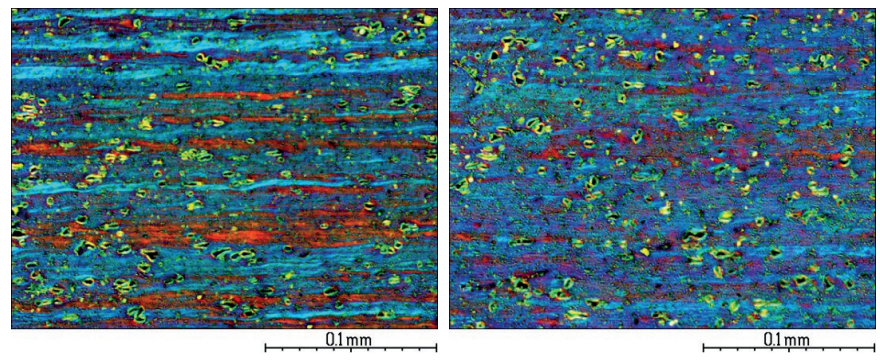

Fig. 11. Photographs of microstructure obtained in the $5 \mathrm{~mm}$ thick AA2519 alloy sheet - section longitudinal (A) and transverse (B) to the sheet rolling direction
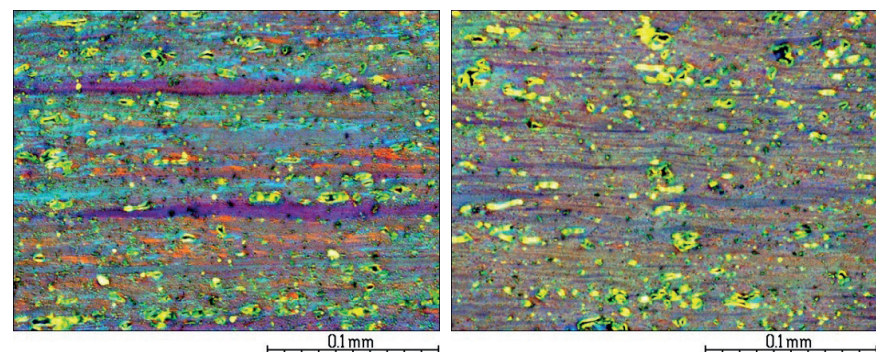

Fig. 12. Photographs of microstructure obtained in the $10 \mathrm{~mm}$ thick AA2519 alloy sheet - section longitudinal (A) and transverse (B) to the sheet rolling direction

Microstructure examinations were carried out on sections longitudinal and transverse to the rolling direction, using sheet metal samples of the thickness of $3 \mathrm{~mm}, 5 \mathrm{~mm}$ and $10 \mathrm{~mm}$. For easier grain identification, the metallographic sections were subjected to additional electrochemical treatment in Barker's reagent. The revealed grains showed the habit typical of rolled products with characteristic morphological texture. The grains were elongated in the rolling direction forming characteristic bands. In all cases, the observed grain size was in the range of $10 \mu \mathrm{m}$ to $100 \mu \mathrm{m}$. The structure also contained the precipitates of intermetallic phases in the form of plates running parallel to the natural sheet surface and precipitates of oblong shapes evenly distributed in the aluminium alloy matrix.

Based on the obtained results of structure examinations it was found that samples of the sheet metal with a thickness of $3 \mathrm{~mm}, 5 \mathrm{~mm}$ and $10 \mathrm{~mm}$ showed similar microstructure in the examined cross-sections, thus confirming that plastic working of these materials was consistent and correct, notwithstanding small differences in the temperature of the beginning and end of rolling and different number of passes through a rolling mill.

The next step was testing of the rolled sheet mechanical properties. The results are shown in Table 3.

TABLE 3

Mechanical properties and hardness of sheets rolled from the AA2519 alloy

\begin{tabular}{|c|c|c|c|c|}
\hline $\begin{array}{c}\text { Thickness } \\
{[\mathrm{mm}]}\end{array}$ & $\begin{array}{c}\text { Yield } \\
\text { strength } \\
{[\mathrm{MPa}]}\end{array}$ & $\begin{array}{c}\text { Tensile } \\
\text { strength } \\
{[\mathrm{MPa}]}\end{array}$ & $\begin{array}{c}\text { Elongation } \\
{[\%]}\end{array}$ & $\begin{array}{c}\text { Hardness } \\
\text { HB }\end{array}$ \\
\hline 3 & 352 & 374 & 4,3 & 89,4 \\
\hline 5 & 296 & 314 & 7 & 84,9 \\
\hline 10 & 211 & 254 & 18 & 79,0 \\
\hline
\end{tabular}

\subsection{Rolling of AA2519 alloy sheets clad with EN AW- $1050 \mathrm{~A}$ alloy}

The aim of the next stage of the research was to determine the feasibility of cladding in a hot rolling process the AA2519 alloy with EN AW-1050A alloy and to develop a technology for practical implementation of this process. To this end, numerous rolling tests were carried out in different variants of the temperature and rolling reduction values with the cladding layer deposited on one or both sides of the clad product. The AA2519 alloy ingots were prepared for cladding by two methods. In the first method, ingots with a crosssection of $300 \times 120 \mathrm{~mm}$ and a length of $340 \mathrm{~mm}$ were initially 
widened to a width of about $600 \mathrm{~mm}$ or rolled to a thickness of about $60 \mathrm{~mm}$ (Fig. 13). Then the EN AW-1050A alloy sheet $3 \mathrm{~mm}$ thick was clad to them on one or both sides (Fig. 13). In the second method, the AA2519 alloy ingots were rolled into the sheets of $15 \mathrm{~mm}$ or $10 \mathrm{~mm}$ thickness (depending on the expected final thickness of the clad product), and onto these sheets, the EN AW-1050A alloy sheet of $3 \mathrm{~mm}$ thickness was clad on one or both sides (Fig. 14). In the first variant, the rolled clad sheet had the thickness of $3 \mathrm{~mm}$ and $10 \mathrm{~mm}$, in the second variant of $3 \mathrm{~mm}$ and $5 \mathrm{~mm}$. Both variants were chosen in such a way as to obtain on the AA2519 core metal and EN AW-1050A cladding layer the rolling reduction ranging from $84 \%$ to $95 \%$ in the first variant and from 72 to $81 \%$ in the second variant. Rolling tests were carried out at different temperatures. Their ranges are given in Table 4, where also examples of the AA2519 alloy rolling process parameters and parameters of the EN AW-1050A cladding alloy are given. The temperature ranges of the rolled strip were lower by approximately $100^{\circ} \mathrm{C}$. Unfortunately, due to typical industrial environment during testing and manual feeding of material for rolling, the temperature drop was not repetitive and did not always faithfully reflect the course of the rolling process (i.e. the number of passes through the rolling mills and the rolling reduction). Sometimes the result depended on a more or less efficient feeding of material to the rolling mill.
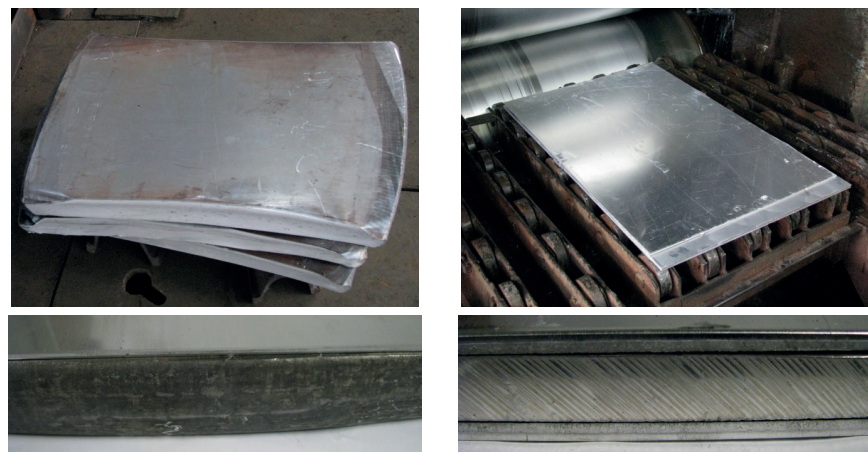

Fig. 13. Ingots of AA2519 alloy widened to $\sim 600 \mathrm{~mm}$ and prepared for rolling and cladding with EN AW-050A alloy (singleside cladding)

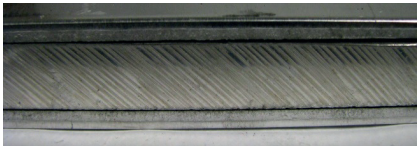

Fig. 14. $10 \mathrm{~mm}$ thick AA2519 alloy sheet with double-side $3 \mathrm{~mm}$ thick clad layer of EN AW 1050A alloy

For all variants, valid sheets were obtained, only sporadically with minor surface defects but without delaminations or lack of bond between the cladding layer and the core. This demonstrates adequate surface preparation and properly chosen conditions of the rolling process, i.e. temperature of the rolled material and rolling reduction. Sheets of the AA2519 alloy of $3 \mathrm{~mm}, 5 \mathrm{~mm}$ and $10 \mathrm{~mm}$ thickness, clad on one or two sides, were used for structure examinations made on the longitudinal and transverse sections to determine the thickness of the resulting cladding layer, the grain size and the quality of bond between the core (AA2519 alloy) and the cladding layer (EN AW-1050A alloy). Examples of the obtained results of structure examinations are shown in Figures 15-18.

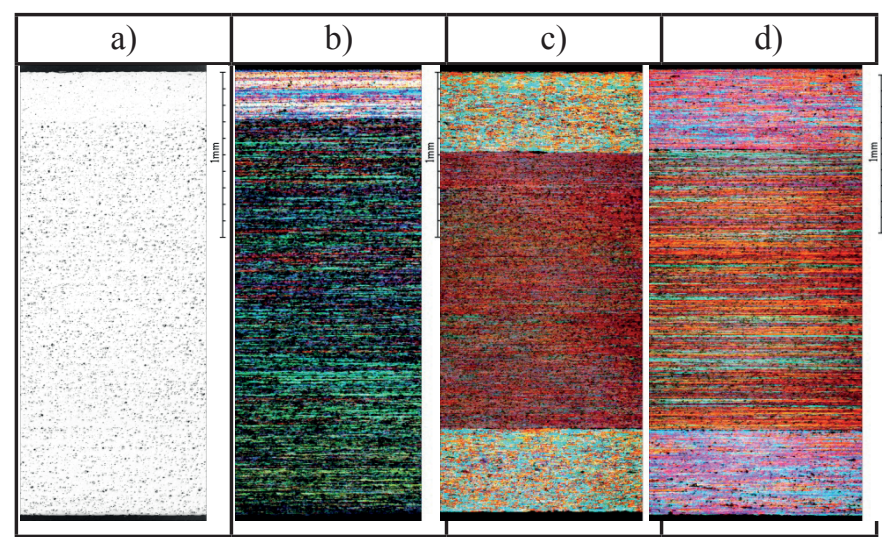

Fig. 15. Microstructures obtained in sheets rolled to a thickness of 3 $\mathrm{mm}$ with single-side cladding (A-transverse section, B-longitudinal section) and double-side cladding (C-transverse section D-longitudinal section)

The structure of the clad sheet samples shows the presence of two layers: the core with the structure of AA2519 alloy and the cladding layer of EN AW-1050A alloy with a thickness of $0.3 \div 0.5 \mathrm{~mm}$ and the structure of pure aluminium. The structure of the cladding layer shows the presence of, typical for pure aluminium, intermetallic precipitates of the Al-Fe-Si type composed of aluminium and major impurities. The precipitates reach the size of $1 \mu \mathrm{m}$ and are evenly distributed in the matrix. The microstructure of both aluminium alloy and the cladding layer is composed of fine grains, elongated in the rolling direction to form characteristic bands, the same as in the sheets rolled without the cladding layer. Studies show absence of a negative effect of the temperature increase on the size of grains (absence of uncontrolled recrystallization and grain growth). The bond produced between the AA2519 alloy core and the EN AW-1050A cladding alloy is continuous and free from the structural and mechanical defects. Figures 16 and 17 show

TABLE 4

Parameters of the rolling process of the AA2519 alloy ingots and sheets combined with cladding

\begin{tabular}{|c|c|c|c|c|}
\hline $\begin{array}{c}\text { Alloy }+ \text { cladd* thickness } \\
{[\mathrm{mm}]}\end{array}$ & $\begin{array}{l}\text { Billet temp. before rolling } \\
\text { proces }\left[{ }^{\circ} \mathrm{C}\right]\end{array}$ & $\begin{array}{l}\text { Billet temp. after rolling proces } \\
\qquad\left[{ }^{\circ} \mathrm{C}\right]\end{array}$ & $\begin{array}{l}\text { Sheet thickness } \\
{[\mathrm{mm}]}\end{array}$ & $\begin{array}{c}\text { Hot deformation } \\
{[\%]}\end{array}$ \\
\hline \multicolumn{5}{|c|}{ variant 1} \\
\hline $\mathrm{S} 60+\mathrm{P} 3$ & $430-480$ & $310-380$ & 3 & 95 \\
\hline S $60+$ P 3 & $430-460$ & $330-360$ & 10 & 84 \\
\hline \multicolumn{5}{|c|}{ variant 2} \\
\hline P $3+$ S $10+$ P 3 & $460-480$ & $310-350$ & 3 & 81 \\
\hline $\mathrm{S} 15+\mathrm{P} 3$ & $430-460$ & $320-340$ & 5 & 72 \\
\hline $\mathrm{P} 3+\mathrm{S} 15+\mathrm{P} 3$ & $430-460$ & $310-360$ & 5 & 76 \\
\hline
\end{tabular}

* Symbols: S - AA2519 alloy, P - layer of EN AW-1050A cladding alloy. 
microstructures obtained in the main variants of the rolling process of the clad sheets, including thickness measurements. For variant 1, where the starting thickness of the slab ingot was uniform and amounted to $60 \mathrm{~mm}$, the cladding thickness on the $3 \mathrm{~mm}$ thick sheet was $0.3 \mathrm{~mm}$, and on the $10 \mathrm{~mm}$ thick sheet it was $0.5 \mathrm{~mm}$. This is the result of more passes and higher values of the rolling reduction anticipated for the metal sheet of $3 \mathrm{~mm}$ thickness. On the other hand, in variant 2, where the starting thickness of the AA2519 sheet varied, similar thicknesses of the cladding layer were obtained for both the $3 \mathrm{~mm}$ and $5 \mathrm{~mm}$ sheet metal, i.e. the cladding layers of $0.4 \mathrm{~mm}$ and $0.45 \mathrm{~mm}$, respectively. This indicates that, despite significant differences in the ductility of the two materials (EN AW-1050 alloy is more deformable at temperatures of about $450^{\circ} \mathrm{C}$ ), with proper selection of the starting thickness of the core alloy and cladding alloy, it is possible to precisely control the cladding-to-core thickness ratio. SEM microstructure (Fig. 18) confirms a very strong bond produced between the AA2519 alloy core and EN AW$1050 \mathrm{~A}$ alloy cladding. There is no mixing of materials, as confirmed by the "Cu" distribution - a large amount in the core alloy and traces in the cladding layer.
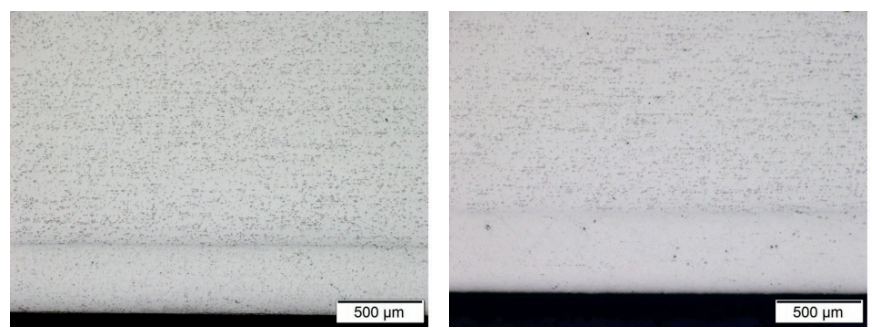

Fig. 16. Microstructure of the clad AA2519 alloy sheets rolled according to variant 1
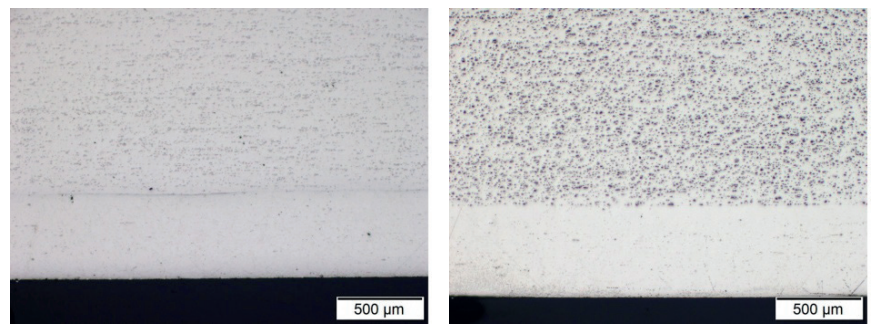

Fig. 17. Microstructure of the clad AA2519 alloy sheets rolled according to variant 2
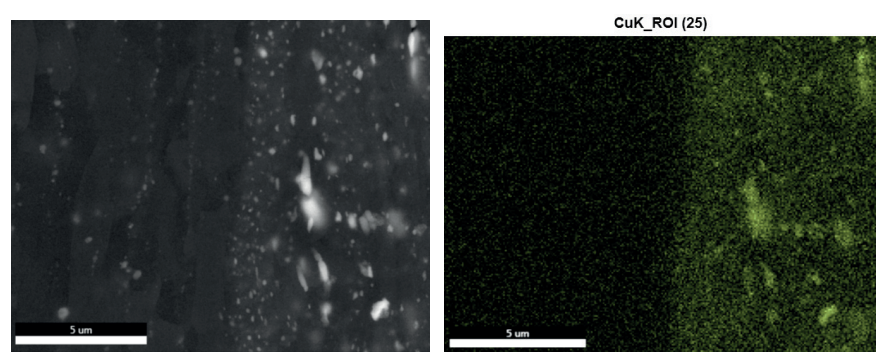

Fig. 18. Example of microstructure obtained in a bond between the AA2519 alloy core and EN AW-1050A alloy cladding (SEM) and surface distribution of $\mathrm{Cu}$

From the clad sheets, samples were taken for hardness measurements (according to the scheme shown in Figure 19) and for the determination of as-rolled static tensile properties. The results are shown in Table 5. Hardness of the cladding layer was higher on the $3 \mathrm{~mm}$ sheet because hardened by higher strain rate. The same situation has occurred in the AA2519 alloy core, as shown by the results of hardness and strength measurements. The clad sheet properties were inferior to those obtained in the AA2519 alloy sheet without cladding. This is mainly due to the fact that the values obtained were averaged for both the AA2519 alloy core and EN AW-1050A alloy cladding, the latter one being characterized by very low mechanical properties. In spite of this, the cladding layer was subjected to the effect of tension equally strong as the core alloy, thus proving a very strong bond produced between the layers.

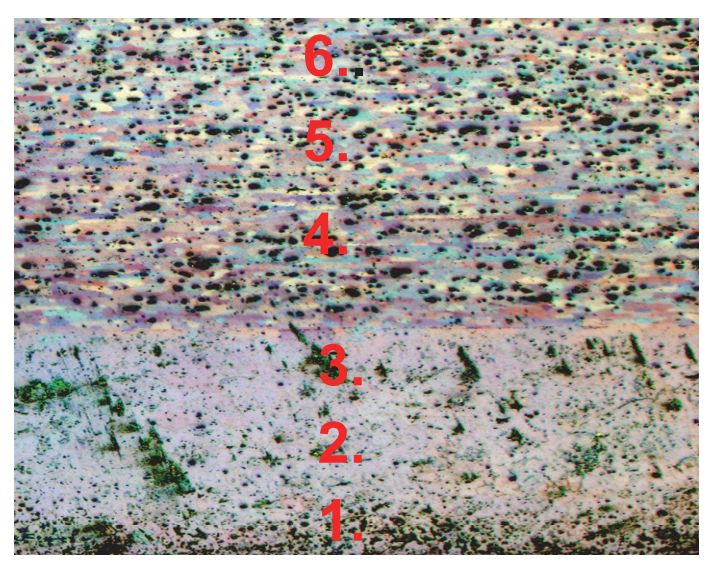

Fig. 19. Scheme of hardness measurement.

Hardness and strength of sheets rolled from the AA2519 alloy clad with EN AW-1050 alloy

\begin{tabular}{|c|c|c|c|c|c|c|c|c|c|}
\hline \multirow{4}{*}{$\begin{array}{c}\text { Thickness (no. } \\
\text { of clad) } \\
{[\mathrm{mm}]}\end{array}$} & \multirow{2}{*}{\multicolumn{6}{|c|}{$\frac{\text { Micro hardness HV0,05 }}{\text { Area of measurement }}$}} & \multicolumn{3}{|c|}{ Mechanical properties } \\
\hline & & & & & & & \multirow{3}{*}{$\begin{array}{c}\text { Tensile strength } \\
{[\mathrm{MPa}]}\end{array}$} & \multirow{3}{*}{$\begin{array}{l}\text { Yield strength } \\
{[\mathrm{MPa}]}\end{array}$} & \multirow{3}{*}{$\begin{array}{c}\text { Elongation } \\
{[\%]}\end{array}$} \\
\hline & \multicolumn{3}{|c|}{ Cladd } & \multicolumn{3}{|c|}{ AA2519 alloy } & & & \\
\hline & 1 & 2 & 3 & 4 & 5 & 6 & & & \\
\hline 3 (1xclad) & 45 & 42 & 42 & 109 & 104 & 102 & 371 & 343 & 5 \\
\hline 3 (2xclad) & 44 & 41 & 42 & 95 & 93 & 99 & 345 & 302 & 6 \\
\hline 10 (1xclad) & 33 & 34 & 34 & 75 & 79 & 75 & 239 & 197 & 14 \\
\hline
\end{tabular}




\section{Conclusions}

1. Parameters and technology of pre-treatment and casting of slab ingots from the AA2519 alloy for further rolling have been developed. The double feeding system ensures better homogeneity of microstructure (less variations in the grain size).

2. The rolling technology of the AA2519 alloy sheets with thicknesses in the range of $3 \div 10 \mathrm{~mm}$ was tested and optimized under the local conditions of the „Labędy” Non-Ferrous Metals Rolling Mill. The temperature range for the beginning of rolling was set at $400 \div 440^{\circ} \mathrm{C}$; the end temperature was set at $>300^{\circ} \mathrm{C}$.

3. A technology was developed for rolling of the AA2519 alloy sheets to thicknesses comprised in the range of $3 \div$ $10 \mathrm{~mm}$, single-side or double-side clad with the EN AW$1050 \mathrm{~A}$ alloy. The rolling parameters producing a strong bond between the $\mathrm{Al}$ alloy core and the cladding layer are as follows: rolling temperature of $430 \div 480^{\circ} \mathrm{C}$ at the beginning and $>320^{\circ} \mathrm{C}$ at the end, rolling reduction $>75 \%$.

4. Analysis of the structure obtained in sheets made from the AA2519 alloy in thicknesses of $3 \mathrm{~mm}, 5 \mathrm{~mm}$ and $10 \mathrm{~mm}$, single-side or double-side clad, has confirmed the correct choice of the rolling process parameters. The microstructure was fine with texture typical of the rolled material. There were no delaminations and voids.

5. In the next part of the research, the manufactured sheets will be subjected to explosive bonding with titanium alloy sheet.

\section{Acknowledgements}

Research was conducted within the Applied Research Programme NCBR in project nr PBS2/A5/35/2013 titled "New, advanced Al-Ti layered materials with enhanced ballistic resistance for aviation and space constructions"; realization period 2013-2016.

\section{REFERENCES}

[1] International Alloy Designations and Chemical Composition Limits for Wrought $\mathrm{Al}$ and Wrought Al Alloys, The Aluminium Association, April (2006).

[2] A. Maranda, J. Nowaczewski, E. Włodarczyk, B. Zygmunt, J. Tech. Pchys 20, 19 (1979).

[3] H. Paul, L. Lityńska-Dobrzańska, M. Miszczyk, M. Prażmowski, -Arch Metall Mater 57, 1151-1162 (2012).

[4] S. Saravanan, K. Raghukandan, Arch Metall Mater 59, 16151618, (2014).

[5] J. Wypart, D. Rydz, G. Stradomski, H. Dyja, Arch Metall Mater 59, 1572, (2014).

[6] http://www.aluminium-konin.com.pl/predefUpload/katalog pl.pdf

[7] B. Płonka, J. Senderski, Key Eng Mat 491, 59-66 (2012)

[8] J. Senderski, B. Płonka, M. Lech-Grega, S. Boczkal, W. Pachla, Arch Mater Sci Eng 39, 97-102 (2009).

[9] J. Senderski, M. Lech-Grega, B. Płonka, Arch Metall Mater 56, 475-486 (2011).

[10] B. Płonka, A. Kłyszewski, J. Senderski, M. Lech-Grega, Arch Civ Mech Eng 8, 2, 149-156 (2008). 
